\title{
Dental Caries Prevalence among 3 - 14 Year Old School Children of Chitwan
}

\author{
Santosh Adhikari, ${ }^{1}$ Lucky Tamrakar, ${ }^{2}$ Manoj Humagain, ${ }^{3}$ Rosina Bhattarai ${ }^{4}$ \\ ${ }^{1,4}$ Lecturer, ${ }^{2}$ General Dental Practitioner, ${ }^{3}$ Professor \\ ${ }^{1,4}$ Department of Community Dentistry, College of Medical Sciences, Bharatpur, Nepal, \\ ${ }^{2}$ Om Sairam Dental Care E Research Center, Ratnanagar, Chitwan, Nepal, \\ ${ }^{3}$ Department of Periodontics, Kathmandu University School of Medical Sciences, Dhulikhel, Nepal.
}

\section{ABSTRACT}

Introduction: Dental caries,an infectious microbiologic disease of dental hard tissues is a global public health problem. It affects people of all ages with the highest priority risk group being school-going children.

Objective: This study was done to assess the prevalence of dental caries in the 3-14 years old school children of Chitwan and to compare it across genders,age groups and school groups.

Methods: This was a cross-sectional study conducted from January 2018 to May 2018 where WHO criteria was used to examine and calculate DMFT and dft (decayed filled teeth) indices among 360 school children. Statistical analysis was done with SPSS 20. Statistical significance was determined using independent t-test and ANOVA test.

Results: The prevalence of the dental caries was found to be $85.83 \%$ with mean DMFT of $3.01 \pm 2.24$ among school children of Chitwan. Caries prevalence was higher in females compared to males, and in government schools compared to private school. Caries experience was highest in middle childhood group 7-12 years $(89.20 \%$, mean "DMFT+dft" $3.56 \pm 2.33)$ followed by late childhood group of 13-14 years (84.72\%,mean DMFT $2.68 \pm 1.95)$ and early childhood group of 3-6 years $(77.33 \%$,mean dft $1.76 \pm$ 1.60) and the differences were statistically significant. The difference in caries experience between private and government school groups as well as in male and female children was not statistically significant. $82.7 \%$ of the children had untreated caries while only $5.83 \%$ had filled teeth in their mouth.

Conclusions: The prevalence of dental caries was higher in middle childhood group and higher percentage of untreated decays, calls for the need of immediate preventive as well as curative interventions.

Keywords: Caries experience; dental caries; filled teeth; prevalence; school children; untreated dental caries.

\section{INTRODUCTION}

Dental caries is the most prevalent and chronic oral disease, particularly in childhood age. ${ }^{1,2}$ It is a common public health problem in school children associated with poor oral hygiene, dietary and dental visit habits. ${ }^{3}$ If untreated it can impact daily activities in terms of play, sleep,eating and school activity. ${ }^{4}$ In children it may cause

\section{Correspondence}

Dr. Santosh Adhikari

Lecturer,

College of Medical Sciences,Bharatpur,Nepal

E-mail: santoshddc@gmail.com

\section{Citation}

Adhikari S, Tamrakar L, Humagain M, Bhattarai R. Dental Caries Prevalence in 3-14 year Old School Children of Chitwan. J Nepal Assoc Pediatr Dent. 2021;2(1):19-23. pain, discomfort, eating disorder, tooth loss, and delayed speech. It also affects children's concentration in school, and at times, dental treatment expense may become certain financial burden on the families. ${ }^{5}$

World Health Organization reports 60-90\% of schoolchildren worldwide have experienced dental caries and it's most prevalent in Asian and Latin American countries. ${ }^{6}$ According to Centers for Disease Control and Prevention (CDC), more than 19\% of children have untreated cavities and approximately $41 \%$ of children have decay in their baby teeth. ${ }^{7}$ The caries percentage in the school going children of Nepal was found to be above the recommended level of the World Health Organization. ${ }^{8}$

The study was done in Chitwan district school children to find the prevalence of dental caries across two genders, 
two socioeconomic strata and three child age groups. Chitwan is rapidly urbanizing region of the country with changing dynamics related to life style factors. ${ }^{9}$

\section{METHODS}

The study was a cross sectional study,employing stratified random sampling method. Ethical approval for the study was obtained from Institutional Review Committee of College of Medical Sciences, Bharatpur. The study was conducted from January 2018 to May 2018. Required permissions were obtained from concerned authorities i.e. principals of each school. Prior consent was also taken from the parents of each child through school authorities.

The school children of Chitwan were stratified based on the category of school they were enrolled in. Children enrolled in government school would represent the low socioeconomic strata while those in private schools would represent the relatively higher socioeconomic strata.10 As such, four government and four private schools were randomly selected for the survey.

To determine sample size, the formula $n=z^{2} p q / d^{2}$, was used with prevalence $(p=63.83 \%)$ taken from a previous study, ${ }^{11}$ that resulted in a minimum sample size of 354 to be taken at $95 \%$ confidence and $5 \%$ precision. Fortyfive students of the age group 3-14 years were randomly selected from each school as sampling units making up a total of 360 .

The children were examined by single qualified examiner in their respective schools seated on an ordinary chair in a broad daylight facing away from direct sunlight, with the help of dental explorer and mouth mirror. Using World Health Organization diagnostic criteria, ${ }^{12}$ the number of decayed teeth, missing teeth and filled teeth (DMFT and/or dft) were recorded and when the examiner was in doubt, no caries was recorded. For the analysis, the students were categorized according to their age group, gender and category of school. Children belonging to 3-6 years were classified as age group I, 7-12 years as agegroup II,and 13-14 as age-group III (Table 1). Only dft was recorded for age group I as they represented the primary dentition group. DMFT as well as dft was recorded for age group II representing mixed dentition and only DMFT was recorded for age group III representing permanent dentition age group. The decay component would indicate the untreated caries. Caries experience: "dft" would indicate in group I, "DMFT+ dft" in group II and
"DMFT" in group III. Students with $(\mathrm{DMFT}+\mathrm{dft})=0$, have no caries experience and students with $(\mathrm{DMFT}+\mathrm{dft})=1$ or $>1$,have caries experience.

Inclusion criteria: Students in age-range 3-14 and students who were present on the day of examination.

Exclusion criteria: Students of age below 3 and above 14 and students who were absent on the day of examination.

Statistical analysis: SPSS 20 was used for data analysis. Independent t-test and ANOVA test were performed to determine the statistical significance.

\section{RESULTS}

Among the 360 children examined, 175 were boys and 185 were girls. 75 (20.8\%) were from age group I, 213 $(59.2 \%)$ from age group II and 72(20.0\%) from age group III. $180(50.0 \%)$ were from private schools and 180 (50.0\%) from government schools.

The prevalence of the dental caries in the school children of Chitwan was found to be $85.83 \%$. Caries prevalence was slightly higher in females $(86.48 \%)$ compared to males (85.14\%) and slightly higher in government schools (87.2\%) compared to private schools (84.4\%) but it was significantly higher in middle childhood group (91.74\%) compared to early childhood group (74.28\%) and late childhood group (86.11\%).

The mean caries experience among the children was $3.01 \pm 2.24$. Mean caries experience was higher in males compared to females but the result wasn't statistically significant. Private schools had more caries experience compared to government schools but the difference wasn't statistically significant. The mean caries experience was highest in middle childhood group of 7-12 years followed by late childhood group and early childhood group and the differences were statistically significant. The mean DMFT was 2.03 and dft was 1.75 in the school children of Chitwan. The details of caries experience in specific age groups, gender groups and school groups, are listed in Table 1.

$82.7 \%$ of the children had tooth/teeth with untreated caries in their mouth. The proportion of females with untreated caries was higher both in private and government schools. The proportion of children with untreated caries was slightly higher in private schools. The figures are depicted in Table 2. 
Table 1. Mean caries experience, untreated caries and filled teeth across gender, age group and category of school.

\begin{tabular}{|c|c|c|}
\hline Variables & $\mathrm{DMFT}+\operatorname{dft}(\mathrm{Mean} \pm \mathrm{SD})$ & $P$ value \\
\hline \multicolumn{3}{|l|}{ Gender $^{\#}$} \\
\hline Male & $3.10 \pm 2.27$ & 0.45 \\
\hline Female & $2.92 \pm 2.22$ & \\
\hline \multicolumn{3}{|l|}{ School $^{\#}$} \\
\hline Private & $3.06 \pm 2.25$ & 0.64 \\
\hline Government & $2.95 \pm 2.24$ & \\
\hline \multicolumn{3}{|l|}{ Age group ${ }^{¥}$} \\
\hline Age group I & $1.76 \pm 1.60$ & $0.00^{*}$ \\
\hline Age group II & $3.56 \pm 2.33$ & \\
\hline Age group III & $2.68 \pm 1.95$ & \\
\hline
\end{tabular}

\# Independent t-test, $\cdot=$ ANOVA test,,$*$ Statistically significant

Table 2. Proportion of children with untreated caries across gender and category of school.

\begin{tabular}{|c|c|c|c|}
\hline & Government school & Private school & Both schools \\
\hline Male & $63(75.9 \%)$ & $75(81.5 \%)$ & $138(79.0 \%)$ \\
\hline Female & $83(85.5 \%)$ & $77(87.5 \%)$ & $160(88.0 \%)$ \\
\hline Both genders & $146(81.1 \%)$ & $152(84.4 \%)$ & $298(82.7 \%)$ \\
\hline
\end{tabular}

Table 3. Proportion of children with filled teeth across gender and category of school.

\begin{tabular}{|c|c|c|c|}
\hline & Government school & Private school & Both schools \\
\hline Male & $2(2.40 \%)$ & $8(8.69 \%)$ & $10(5.71 \%)$ \\
\hline Female & $1(1.03 \%)$ & $10(11.36 \%)$ & $11(5.94 \%)$ \\
\hline Both genders & $3(1.60 \%)$ & $18(10.00 \%)$ & $21(5.83 \%)$ \\
\hline
\end{tabular}

While caries experience was present in $85.83 \%$ of the population, only $5.83 \%$ of the children had filled tooth/ teeth in their mouth. The proportion of children with filled teeth was higher in private schools and in females as depicted in Table 3.

\section{DISCUSSION}

The high caries prevalence of dental caries in the school children of Chitwan indicates enormity of oral health problems in the district. The caries prevalence of $85.83 \%$ reported in the study is much higher than the targets of national strategic plans according to National Oral Health Policy 2070, Ministry of Health, Nepal. ${ }^{13}$ The caries prevalence is higher compared to many similar studies. ${ }^{14-18}$ The high mean DMFT could be the reflection of increased sugary and fast-food consumption in this rapidly urbanized district.

In the study, caries prevalence in females was higher than in males similar to the findings of Misra FM et al. ${ }^{19}$ but dissimilar to the findings of others. ${ }^{20-22}$ The higher prevalence of caries in females could be due to their different salivary composition and flow rate, hormonal fluctuations, dietary habits, genetic variations, and particular social roles among their family. ${ }^{23}$ It may also be due to the earlier eruption of teeth in them compared to males. ${ }^{24}$ Our study showed no significant difference in caries experience across genders which was in contrast to the findings of Bhagat TK, ${ }^{14}$ Goenka $\mathrm{P}^{20}$ and Mwakatobe AJ. ${ }^{25}$

This study observed, higher prevalence of caries and higher caries experience in middle childhood age group, which is consistent with the findings in Bundelkhand, ${ }^{15}$ and in Orissa, ${ }^{26}$ but in contrast to a study in Manglore. ${ }^{22}$ The decline in the caries rate from middle childhood age to late childhood age may be due to the increased awareness of oral hygiene in the higher age group. This is supported by the finding of $\mathrm{Chu} \mathrm{CH}$ et al. ${ }^{27}$ who found $44 \%$ and $22 \%$ of caries rate in 6 and 12 year old children respectively, who had never brushed in their study population showing improvement in oral hygiene practices with age. 
Our study shows that the major proportion of children had untreated caries with a very low proportion of the children having filled teeth, similar to a recent study by Tarik Shounia et al. ${ }^{17}$ This may be due to the overrated opinion of the parents regarding the oral health status of their children, ${ }^{28}$ high costs of dental treatment ${ }^{29}$ and the lack of awareness regarding oral health in the parents and children. ${ }^{30}$ The higher proportion of females with untreated caries seen in the study may be due to the neglect to female children compared to male children by their parents. The difference in proportion of children with filled teeth in government and private schools is probably the consequence of socioeconomic gap between the children studying in the two different settings.

Limitation: The caries experience could be prone to recall bias,particularly for the missing teeth (MT).

\section{CONCLUSIONS}

The study shows that caries prevalence is very high in the school children of Chitwan,with the highest burden among middle childhood age of 7 to 12 years with significant proportion of the children having untreated caries. Thus, the need of intervention through both preventive and curative approach seems urgent.

\section{AGKNOWLEDGEMENTS}

I would also like to thank all the schools,parents and the children who have agreed to participate in our research.

Conflict of Interest: None

\section{REFERENGES}

1. Okoye L,Ekwueme O. Prevalence of dental caries in a nigerian rural community: a preliminary local survey. Ann Med Health Sci Res. 2011 Jul;1(2):187-95. [PubMed | Full Text]

2. Dawkins E,Michimi A,Ellis-Griffith G,Peterson T,Carter D,English G. Dental caries among children visiting a mobile dental clinic in South Central Kentucky: a pooled cross-sectional study. BMC Oral Health. 2013 May 2;13:19. [uㅣㄹed | DOI]

3. Mulu W,Demilie T,Yimer M,Meshesha K,Abera B. Dental caries and associated factors among primary school children in Bahir Dar city: a cross-sectional study. BMC Res Notes. 2014 Dec 23;7:949. [ubMed | DOI]

4. Mafuvadze BT,Mahachi L,Mafuvadze B. Dental caries and oral health practice among 12 year old school children from low socio-economic status background in Zimbabwe. Pan Afr Med J. 2013 Apr 29;14:164. [PubMed I DOI]

5. Bramantoro T,Setijanto RD,Palupi R,Aghazy AZ,Irmalia WR. Dental Caries and Associated Factors among Primary School Children in Metropolitan City with the Largest Javanese Race Population: A Crosssectional Study. Contemp Clin Dent. 2019 Apr-Jun;10(2):274-283. [PubMed | DOI]

6. Prasai Dixit L,Shakya A,Shrestha M,Shrestha A. Dental caries prevalence,oral health knowledge and practice among indigenous Chepang school children of Nepal. BMC Oral Health. 2013 May 14;13:20. [PubMed | DOI]

7. Samadi D. Dental hygiene important for whole body,not just your smile. Fox News. Fox News. 2012. Retrieved 26 Feb 2021. Available from: https://www.foxnews. com/health/dental-hygiene-important-for-whole-body-not-just-your-smile. [Link]

8. Subedi B,Shakya P,KC U,Jnawali M,Paudyal BD,Acharya A,Koirala S,Singh A. Prevalence of dental caries in 5 - 6 years and 12 - 13 years age group of school children of Kathmandu valley. JNMA J Nepal Med Assoc. 2011 Oct-Dec;51(184):176-81. [PubMed]

9. Bakrania,S. Urbanisation and urban growth in Nepal (GSDRC Helpdesk Research Report 1294) Birmingham,UK: GSDRC,University of Birminham. 2015. Retrieved 26 Feb 2021. Available from: https://gsdrc.org/publications/urbanisation-and-urban-growth-in-nepal/. [․ull Text | Link]

10. Koirala A. Debate on Public and Private Schools in Nepal. Int. J. of Management and Social Sciences 2015; 2(1): 3-8. [ Full Text | DOI]

11. Moses J,Rangeeth BN,Gurunathan D. Prevalence of dental caries,socio-economic status and treatment needs among 5-15 year old school going children of Chidambaram. J ClinDiagn Res. 2011;5:146-51. [Full Text]

12. World Health Organization. Oral Health Surveys: Basic Methods,5th ed. Geneva,Switzerland: World Health Organization; 2013. Retrieved 26 Feb 2021. Available from: https://apps.who.int/iris/handle/10665/97035. [Link]

13. National oral health policy. Retrieved 26 Feb 2021. Available from: https://www.mohp.gov.np. [Full Text]

14. Bhagat TK,Shrestha A. Prevalence of dental caries among public school children in Eastern Nepal. Journal of Chitwan Medical College 2014; 4(1): 30-32. [Full $\underline{\text { Text }} \mid \underline{\text { DOI }]}$

15. Jain AJain V,Suri SM,Jain RK. Prevalence of dental caries in male children from 3 to 14 years of age of Bundelkhand region,India. Int J Community Med Public Health. 2016; 3(4): 787-790. [Full Text I DOI]

16. Yee R,Mishra P. Nepal National Oral Health 'Pathfinder' Survey 2004. Kathmandu,Nepal: Oral Health Focal Point,Ministry of Health,HMG Nepal,2004. Retrieved 26 Feb 2021. Available from: http:/www.drbijaytamang.com.np/2018/11/part-of-nepal-national-oral-health.html. [Full Text]

17. Tarik Shounia.,Salwa Atwan,Divesh Byrappagari. Dental Caries Prevalence and Untreated Caries among Children in a School-Based Dental Health Program Using dft/DFT and Significant Caries Index (SCI). Acta Scientific Dental Sciences 2019;3(10): 26-31. [Full Text I DOI]

18. Khanal S,Bhattarai R, Rao NG,Shrestha S. Prevalence of Dental Caries among Primary School Children of Kathmandu District- A Pilot Study. JCMS Nepal. 2017;13(2):275-8. [Full Text | DOI] 
19. Misra FM,Shee BK. Prevalence of dental caries in school going children in an urban area of South Orissa.J Indian Dent Assoc. 1979 Sep;51(9):267-70. [PublMed]

20. Goenka P,Dutta S,Marwah N,Sarawgi A,Nirwan M,Mishra P. Prevalence of Dental Caries in Children of Age 5 to 13 Years in District of Vaishali,Bihar,India. Int J Clin Pediatr Dent. 2018 Sep-Oct;11(5):359-364. [ublMed I DOI]

21. Aukland S,Bjelkaroey J. The dental health of school children in Betul district Madhya Pradesh. J Indian Dent Assoc. 1982 Oct;54(10):367-9. [피Med]

22. Sudha P,Bhasin S,Anegundi RT. Prevalence of dental caries among 5-13-year-old children of Mangalore city. J Indian Soc Pedod Prev Dent. 2005 Jun;23(2):74-9. [PubMed | DOI]

23. Ferraro M,Vieira AR. Explaining gender differences in caries: a multifactorial approach to a multifactorial disease. Int J Dent. 2010;2010:649643. [피 bMed I DOI]

24. Rozzi,FR. Diversity in tooth eruption and life history in humans: illustration from a Pygmy population. Sci. Rep. 2016;6(1):27405. [DOI]

25. Mwakatobe AJ,Mumghamba EG. Oral health behavior and prevalence of dental caries mamong 12-year-old school children in Dar-es-Salaam,Tanzania. Tanzan Dent J. 2007; 14:1-7. [ Full Text | DOI]

26. Vaish RP. Prevalence of caries among tribal school children in Phulbani district,Orissa. J Indian Dent Assoc. 1983 Nov;55(11):454-7. [PubMed]

27. Chu CH,Wong AW,Lo EC,Courtel F. Oral health status and behaviours of children in rural districts of Cambodia. Int Dent J. 2008 Feb;58(1):15-22. [PubMed I DOI]

28. Al-Batayneh OB,Al-Khateeb HO,Ibrahim WM,Khader YS. Parental Knowledge and Acceptance of Different Treatment Options for Primary Teeth Provided by Dental Practitioners. Front Public Health. 2019 Nov 7;7:322. [필ed | DOI]

29. Thompson B,Cooney P,Lawrence H,Ravaghi V,Quiñonez C. The potential oral health impact of cost barriers to dental care: findings from a Canadian population-based study. BMC Oral Health. 2014 Jun 25;14:78. [피Med | DOI]

30. Khanduri N,Singhal N,Mitra M,Rohatgi S. Knowledge,attitude,and practices of parents toward their children's oral health: A questionnaire survey in Bhairahawa (Nepal). Int J Pedod Rehabil 2018;3:59-61. [Full Text I DOI] 